\title{
FACTORS OF CONSUMER BEHAVIOR THAT AFFECT PURCHASING DECISIONS ON BLACKBERRY SMARTPHONE
}

\author{
Muhammad Tony Nawawi \\ Management Departement, Faculty of Economics, Tarumanagara University \\ Jl. Letjen S. Parman No. 1, Jakarta Barat 11440, Indonesia \\ tonynawawi@yahoo.com
}

\begin{abstract}
This study aimed to determine factors of consumer behavior that affect to purchasing decision on BlackBerry Smartphone with the case study in Faculty of Economics, Tarumanagara University, Jakarta. The population was all students of faculty of economics who used or were familiar with the BlackBerry brand mobile phone, with a sampling technique used was purposive random sampling and samples were taken by 200 students. The purpose of the study was to examine and analyze some factors that affect students in the decision to buy BlackBerry mobile phone brands and know the dominant factors that influence the purchase decision. The analysis used the method of multiple regression analysis and hypothesis testing and also testing conducted validity and reliability by using the help of SPSS (Statistical Program for the Science Society). The analysis shows that there is significant positive effect between the factors of cultural, social, personal, and psychological effect on purchasing decisions, with significance 0,000 <0,05, and Adjusted $R$ Square is worth 0,216, it means that $21,6 \%$ of purchase decisions are influenced by these factors.
\end{abstract}

Keywords: consumer behavior, purchasing decisions, student decisions, smartphone.

\section{INTRODUCTION}

The development of mobile phones today has very rapidly increased, where the function of a mobile phone is not just as distance communication, but also to provide service convenience, comfort, and entertainment for its users. For example, it can be used to access the internet, email, social networking, music, video, games, and other features. Today, the consumers who use the mobile phone are widely exposed to various types of products. Each of them races to innovate products with different types, models, and technology, and then they tailor it to the needs of the profession, lifestyle, as well as an interest or hobby users. According to Uddin, et. al., (2014), the mobile phone has diverse usages to different users in accordance with their necessities. With the dramatic increase in mobile phone usage in recent years, people take into account various factors while they decide to purchase a mobile phone. This study has put efforts to uncover the underlying factors those affect customers in choosing the mobile phone.

One product of mobile phones is BlackBerry as a brand product from a manufacturer of mobile phones, in addition to the type of Nokia, Ericsson, and Motorola is produced by Research In Motion. Blackberry is first introduced in 1997 by the Canadian company, Research In Motion that founded by a Greek immigrant in city Waterloo, Canada. BlackBerry is a wireless handheld device phone that has the ability to push e-mail, facsimile, the Internet, BlackBerry Messenger, and various other wireless capabilities. Privileged BlackBerry mainly lies in the push e-mail. By this service, customers can simply receive emails as quickly and easily receive SMS (short message service). The original email has size $1 \mathrm{Mb}$, but if it is accepted by the facility of BlackBerry push e-mail, the size could be $10 \mathrm{~kb}$ with fixed contents. Besides that, the BlackBerry can also easily display attachment file 
formats such as PDF or Microsoft offices like Microsoft word, Microsoft excel, and Microsoft power point. Nowadays consumer behaviors are very important for companies which aim to be successful in such an intensely competitive environment. To cope with intense competition and to influence consumer behaviors is inevitable for companies to consider the cultural, social, psychologic, and personal status of consumers. The main aim of the companies is to get the profit; therefore companies should understand behaviors of their consumers to keep the permanency of the situation and customers in buying their products. In this study, the factors affecting the consumers' behaviors such as age and lifetimes, occupation, lifestyle, and personality are studied (Yakup \& Jablonsk, 2012).

Blackberry begins to tune the consumer since first introduced in Indonesia at mid-December 2004 by the operator Indosat and Starhub company. The users of mobile brands Blackberry now are not executives anymore, but it has spread to the general public, especially the students. It makes BlackBerry sales increase extraordinary rapid in Indonesia and can easily be found in the various mobile phone shop. The use of BlackBerry is now no longer to simply meet the requirements as a means of communication and information alone but has spread to the lifestyle because it gives the impression of the latest lifestyle trends and metropolis. Related to this BlackBerry mobile communication device, the researchers want to know the dominant factors that can affect the users of BlackBerry mobile phones in buying this product, especially consumers' student at the Faculty of Economics, Tarumanagara University Jakarta.

Based on that background, this study is conducted to determine (1) Do the cultural factors have an influence on the decision to students in buying mobile brands BlackBerry? (2) Do the social factors have an influence on the decision to the student in buying mobile brands BlackBerry? (3) Do the personal factors have an influence on the decision to the student in buying mobile brands BlackBerry? (4) Do the psychological factors have an influence on the decision to the student in buying mobile brands BlackBerry? (5) Do the cultural, social, personal, and psychological factors have an influence on student's decision in buying mobile brands BlackBerry?

While the purpose of this study is to empirically examine (1) The influence of cultural factors on product purchasing decisions of BlackBerry brand mobile phone on the student in Faculty of Economics, Tarumanagara University. (2) The influence of social factors on product purchasing decisions of BlackBerry brand mobile phone on the student in Faculty of Economics, Tarumanagara University. (3) Personal factors influence the purchasing decision of BlackBerry brand mobile phone products at the student Faculty of Economics, Tarumanagara University. (4) The influence of psychological factors on product purchasing decisions of BlackBerry brand mobile phone on student Faculty of Economics, Tarumanagara University. (5) The influence of cultural, social, personal, and psychological on product purchasing decisions of BlackBerry brand mobile phone on students of Faculty of Economics, Tarumanagara University. The results of this study are expected to be useful to increase knowledge and understanding consumer behavior in purchasing decisions and can be used as resources in the improvement of marketing strategies according to the needs of consumers.

\section{METHODS}

The population in this study are all the students in the Faculty of economic, Tarumanagara University that uses BlackBerry mobile brands. The sampling technique used in this research is purposive random sampling, which is one type of samples taken nonprobability sampling. Where it has been determined the goal, which is expected to achieve the objectives of this study. The sample in this study is 200 students of economic faculties Tarumanagara University that uses/and knows mobile brands BlackBerry by distributing the questionnaires to students to be filled by the conditions. 
The validity test is used to determine the level of validity of the instrument (questionnaire) that used in data collection. This kind of test is performed to determine whether the items presented in the questionnaire really able to express exactly what will be studied. It is obtained by any score indicators correlate with the total score of the indicator variable, then the correlation results are more than the critical value at 0,05 significant level. An instrument is said to be valid if it is able to measure what is desired, and the high and low of the validity of the instrument indicates the extent to which the data collected does not deviate from the description of the variables in question. According to Sugiyono (2012), "the means used is the analysis of items, where each value in each of the questions are correlated with the total value of all questions to a variable that using the product moment correlation formula". The minimum requirement that is considered valid is the value of $r$ count $>r$ table of values. Or a question is declared as invalid if the item total correlation value correction that question has the value greater than or equal 0,30 . The value of validity test of these variables can be seen in Table 1.

Table 1 Item-Total Statistics

\begin{tabular}{lc}
\hline \multicolumn{1}{c}{ Variabel } & Valid (Corrected Item-Total Correlation) \\
\hline Culture & 0,469 \\
Social & 0,449 \\
Personal & 0,606 \\
Psychological & 0,449 \\
Purchasing Decision & 0,508 \\
\hline \multicolumn{2}{c}{ Source: Primary Data (Processed SPSS) }
\end{tabular}

Based on primary data that has been processed with SPSS, then each item-total correlation weighting variables have values above 0,30 as the minimum requirement. This shows that all the variables in this study declared invalid, as seen in Table 2.

Table 2 Reliability Statistics

\begin{tabular}{lcc}
\hline \multicolumn{1}{c}{ Variabel } & Cronbach's Alpha & N of Items \\
\hline Culture & 0,649 & 3 \\
Social & 0,629 & 3 \\
Personal & 0,765 & 3 \\
Psychological & 0,630 & 3 \\
Purchasing Decision & 0,687 & 3 \\
\hline \multicolumn{2}{c}{ Source: Primary Data (Processed SPSS) }
\end{tabular}

Source: Primary Data (Processed SPSS)

Reliability testintends to determine the consistency of measuring instruments in use or in other words the instruments have consistent results when used repeatedly at different times.Arikunto (2010) has said that for reliability test used Cronbach Alpha technique, in which an instrument can be said to be reliable if you have or alpha reliability coefficient of 0,6 or more. Based on primary data that has been processed and analyzed using SPSS, then each item Cronbach's Alpha generates weighting variables Cronbach alpha values $>0.60$ as the minimum requirements. It shows that all the variables in this study revealed reliable.

Based on the analysis using SPSS, it can be seen the hypothesis testing in Table 3. 
Table 3 T test

\begin{tabular}{llccccc}
\multicolumn{8}{c}{ Coefficients $^{\mathbf{a}}$} \\
\hline \multirow{2}{*}{ Model } & \multicolumn{2}{c}{$\begin{array}{c}\text { Unstandardized } \\
\text { Coefficients }\end{array}$} & $\begin{array}{c}\text { Standardized } \\
\text { Coefficients }\end{array}$ & t & Sig. \\
\cline { 2 - 4 } & B & Std. Error & Beta & & \\
\hline $1 \quad$ (Constant) & 1,087 & 0,251 & & & 4,327 & 0,000 \\
Culture & 0,171 & 0,076 & 0,197 & 2,252 & 0,025 \\
Social & 0,134 & 0,063 & 0,154 & 2,125 & 0,035 \\
Personal & 0,060 & 0,055 & 0,074 & 1,087 & 0,278 \\
Psychological & 0,189 & 0,066 & 0,217 & 2,887 & 0,004 \\
\hline
\end{tabular}

a. Depenent Variable: Purchasing Decision

Source: Primary Data (Processed SPSS)

Based on the results of Table 3, the regression equation can be formulated as follows :

$$
\mathrm{Y}=1,087+0,171 \mathrm{X} 1+0,134 \mathrm{X} 2+0,060+0,189 \mathrm{X} 3 \mathrm{X} 4+\mathrm{e}
$$

Explanation of the results of the regression equation in Table 3 is If $\mathrm{X} 1, \mathrm{X} 2, \mathrm{X} 3$, and $\mathrm{X} 4$ value $=0$, then the sum of the values of $Y=1,087$ units. If there is a change to value $X 1$ for one unit and the other variables constant, the value of $Y$ will experience an increase by 0,171 units. While if there is a change to value $\mathrm{X} 2$ by 1 unit and the other variables constant, the value of $\mathrm{Y}$ will experience an increase by 0,134 units. If there is a change to value $\mathrm{X} 3$ for 1 unit and the other variables constant, the value of $\mathrm{Y}$ will experience an increase by 0,060 units. If there is a change to the value $\mathrm{X} 4$ by one unit and the other variables constant, the value of $Y$ will experience an increase by 0,189 units.

Explanation t-test results of each variable to answer the hypothesis in this study is as following (1) Based on the results of the analysis conducted on SPSS calculations that significant value cultural variables, which means sig $0,025<0,05$. In addition, the t count equal to 2,252 is bigger than $\mathrm{t}$ table with the $5 \%$ significance produced $\mathrm{t}$ table of 1,645 . Therefore, the hypothesis Ho is rejected, and $\mathrm{Ha}$ is accepted hypothesis. This means that there is the significant influence of cultural factors on purchasing decisions. (2) Based on the results of the analysis conducted on SPSS calculation that values the significance of social variables, which means sig $0,035<0,05$. In addition, the results amounted to $2,125 \mathrm{t}$ arithmetic is greater than $\mathrm{t}$ table with the $5 \%$ significance produced $\mathrm{t}$ table of 1,645. Therefore, the hypothesis Ho is rejected, and Ha is accepted hypothesis. This means that there is significant influence of social factors on purchasing decisions. (3) Based on the results of the analysis conducted on the calculation of SPSS that the significant value of the private variable of 0,278 which means sig $<0,05$. In addition, the results amounted to $1,087 \mathrm{t}$ is smaller than the $\mathrm{t}$ table with the $5 \%$ significance produced t table of 1,645 . Therefore, the hypothesis Ho is accepted, and $\mathrm{Ha}$ is rejected hypothesis. This means that there is no significant influence of personal factors on purchasing decisions. (4) Based on the results of the analysis conducted on the calculation of SPSS that psychological variables the significant value of 0,004 , which means sig $<0,05$. In addition, the results amounted to $2,887 \mathrm{t}$ arithmetic is greater than $\mathrm{t}$ table with the $5 \%$ significance produced $\mathrm{t}$ table of 1,645. Therefore, the hypothesis Ho is rejected, and Ha is accepted hypothesis. This means that there is significant influence of psychological factors on purchasing decisions. (5) Based on the results of the analysis conducted on the calculation of SPSS (Test results from F/Test ANOVA) that the value of variable significance of 0,000 which means sig $<0,05$. In addition, the results amounted to $14,705 \mathrm{~F}$ count is greater than the $\mathrm{F}$ table with the $5 \%$ significance and df 4 and 195 produced 2,467 $\mathrm{F}$ table. Therefore, the hypothesis Ho is rejected, and $\mathrm{Ha}$ is accepted hypothesis. This means that there is significant influence of cultural, social, personal, and psychological simultaneously on purchasing decisions. 
Table 4 Model Summary

\begin{tabular}{|c|c|c|c|c|}
\hline Model & $\mathbf{R}$ & R Square & Adjusted R Square & Std. Error of the Estimate \\
\hline 1 & $0,481^{\mathrm{a}}$ & 0,232 & 0,216 & 0,66249 \\
\hline
\end{tabular}

Table 4 explains that the regression coefficient $(\mathrm{R})$ of $0,481(48,1 \%)$, which means independent variables that can explain the effect of $48,1 \%$ and the remaining $51,9 \%$ is explained by other variables outside this research model.Below is the result off test that are made:

Table 5 ANOVA ${ }^{b}$

\begin{tabular}{llccccc}
\hline & Model & Sum of Squares & Df & Mean Square & F & Sig. \\
\hline 1 & Regression & 25,815 & 4 & 6,454 & 14,705 & $0,000^{\text {a }}$ \\
& Residual & 85,584 & 195 & 0,439 & & \\
Total & 111,399 & 199 & & & \\
\hline
\end{tabular}

a. Predictors: (Constant), Psychological, Personal, Social, Cultural

b. Depenent Variable: Purchasing Decision

Based on the results from Table 5, it can be seen the significance of a variable factor of cultural, social, personal, psychological, and purchasing decisions is 0,000 . It means that compared to the alpha $(\alpha)=0,05$, the value is still below it, so that it can be concluded that the concurrent significant influence these factors influence consumer purchasing decisions, or at least one variable $\mathrm{X}$ affects $\mathrm{Y}$ with a $95 \%$ confidence level.

\section{RESULTS AND DISCUSSIONS}

Consumer behavior by Swastha et al., (2012) is defined as the activities of individuals who are directly involved in obtaining and using goods and services, including the decision-making process on the preparation and determine the specific activities. While according to Schiffman, et al., (2011), consumer behavior is the behavior exhibited by consumers in search of the purchase, use, evaluation and replacement products, and services that able to satisfy their needs. Factors that influence consumer behavior is the cultural, social, personal, psychological. Most of these factors are not considered by marketers but in fact should be taken into account to determine how far the factors that affect consumer behavior consumer purchases (Kotler \& Keller, 2012). It can be seen in Figure 1.

Factors that influence consumer behavior is the cultural, social, personal, psychological. Most of these factors are not considered by marketers but in fact should be taken into account to determine how far the factors that affect consumer behavior consumer purchases (Kotler \& Keller, 2012). It can be seen in Figure 1.

\begin{tabular}{|l|l|l|l|}
\hline $\begin{array}{l}\text { Cultural factors : } \\
\text {.Culture }\end{array}$ & $\begin{array}{l}\text { Social factors : } \\
\text {.Subcultures } \\
\text {.Social class }\end{array}$ & $\begin{array}{l}\text { Personal factors : } \\
\text {.Age } \\
\text {.Family } \\
\text {.Work economic } \\
\text {.Roles and Status }\end{array}$ & $\begin{array}{l}\text { Psychological factors : } \\
\text {.Motivation } \\
\text {.Perception learning } \\
\text {.Attitude }\end{array}$ \\
\hline
\end{tabular}

Figure 1 Factors Affecting Consumer Behavior (Source: Kotler \& Keller, 2012) 
Figure 1 states that culture is what determining the desire and behavior to get the most basic values, perceptions, preferences, and behaviors of other important institutions. Cultural factors provide the most comprehensive and influence in the behavior of consumers. Marketers need to know the role played by culture, subculture, and social class. Culture is a set of basic values, perceptions, desires, and behavior that learned by a member of the community of family and other important institutions. According to Kotler and Armstrong (2012) have included in this culture is a culture shift as well as the values in the family. While subculture is a group of people with a separate value system based on experience and common life situations. Sub-cultures include nationality, religious, racial, and geographic region. And then the social class division of society is relatively permanent and organized by the members embraced the values, interests, and behavior that are similar.

Social class division of society is relatively homogeneous and permanent structured hierarchically and whose members embrace the values, interests, and similar behavior. Social class is determined by a single factor, such as revenue but measured as a combination of occupation, income, education, wealth, and other variables. In some social systems, members of different classes maintain a certain role and cannot change their social position. Consumer behavior is also influenced by social factors, namely group, family, and the role and status.

The group is two or more people who interact to achieve individual or collective goals. Some of the primary groups that have a regular but informal interaction, such as family, friends, neighbors, and colleagues. Some of the secondary group, which has a more formal interaction and less regular. It includes organizations such as religious groups, professional associations, and unions. While the family is the organization that most important purchased by consumers in the community and have been thoroughly studied. Marketers are interested in the role and influence of the husband, wife, and children in purchasing a variety of products and services. Whereas, role consists of expected activity carried out by someone according to people who are nearby. Each role carries a status reflecting an award that given by people. People often choose products that show their status in society.

The personal factor is defined as a person's psychological characteristics that are different from other people to cause a response relatively consistent and enduring to the environment. Buying decisions are also influenced by personal characteristics, namely (1) The age and stage of life cycle. People change the goods and services that they buy during his lifetime. Taste for food, clothing, furniture, and recreation are often associated with age. Buying is also shaped by the family life cycle stages that may be passed by the family in accordance with maturity. Marketers often determine the target market in the form of life cycle stages and develop appropriate products and marketing plans for each stage. (2) Work, one's job affects goods and services that they purchase. Marketers try to identify the occupational groups who have an interest in the above-average products and services. A company can even specialize in marketing the product according to specific occupational groups. (3) The economic situation, the current economic situation will affect the choice of products. Marketer of products that are sensitive to income observing trends in personal income, savings, and the level of interest. When the economic indicators point to recession, marketers can take steps to redesign, reposition, and change the product's price. (4) Lifestyle, the pattern of a person's life that is embodied in the activities (work, hobbies, shopping, sports, social activities), interests (food, fashion, family, recreation), and opinions that are more than just a social class and a person's personality, lifestyle featuring patterns react and interact with someone overall in the world. (5) Personality and SelfConcept, personality of each person clearly affect behavior to buy it. Personality refers to the unique psychological characteristics that cause a response relatively consistent and enduring to the environment itself. Personality is usually described in terms of properties such as self-confidence, dominance, easy to get along, autonomy, self-defense, adaptability, and aggressiveness. Personality can be useful for analyzing consumer behavior for the selection of specific products or brands. The last factor that influences consumer behavior is psychological factors. It is as part of the influence of environment where someone's live in the presentwithout ignoring the influence of the past or anticipating the future. 
Consumer decision in buying a product is influenced by many factors, both from within oneself and from beyond the self or the environment. Consumer behavior is a process a customer in making a buying decision, using and set goods and services purchased including the factors that influence purchasing decisions and product usage (Lamb et al., 2010). The main factor influencing consumer behavior is the need factors such as culture and social class. Meanwhile, according to Berkowitz (2010), there are four factors affecting consumer purchase decisions, some of them are socio-cultural influences.

The main factor influencing consumer behavior is the need factors such as culture and social class. Social factors such as the reference group, the family, the role and social status of consumers, personal factors such as age, stage of life cycle, personality and self-concept, and psychological factors such as motivation, perception, learning beliefs, and attitudes. Meanwhile, according to Berkowitz (2010), there are four factors that influence consumer purchase decisions, namely the influence of situational (situational influences), the psychological influences, the influence of sociocultural, and the influence of marketing mix.

While, the main factor influencing consumer behavior is the need factors such as culture and social class. Personal factors such as age, stage of life cycle, personality and self-concept also influence consumer purchase decisions. According to Berkowitz (2010), there are four factors that influence consumer purchase decisions, namely the influence of situational, the psychological influences, the influence of socio-cultural, and marketing mix influences. From these four factors, psychological factors are factors that arise from the consumers themselves. Berkowitz (2010) has said that psychological factors that influence consumer decisions can be translated into five variables, namely motivation, personality, perception, attitude, and lifestyle. These five variables also give influence to the brand image in the minds of consumers. Psychological factors include motivation, perception, learning beliefs, and attitudes. There are four factors that influence consumer purchase decisions that one of them is a psychological impact (psychological influences), in which psychological factors are factors that arise from within consumers. Psychological factors that influence the consumer's decision can be translated into five variables, namely motivation, personality, perception, attitude, and lifestyle (Berkowitz, 2010).

This hypothesis is a temporary answer to the problem of research that the truth remains to be tested empirically. Fromthe formulation ofthe problem, research objectives, the theoretical basis, which have been embodied in a theory can be seen in Figure 2 .

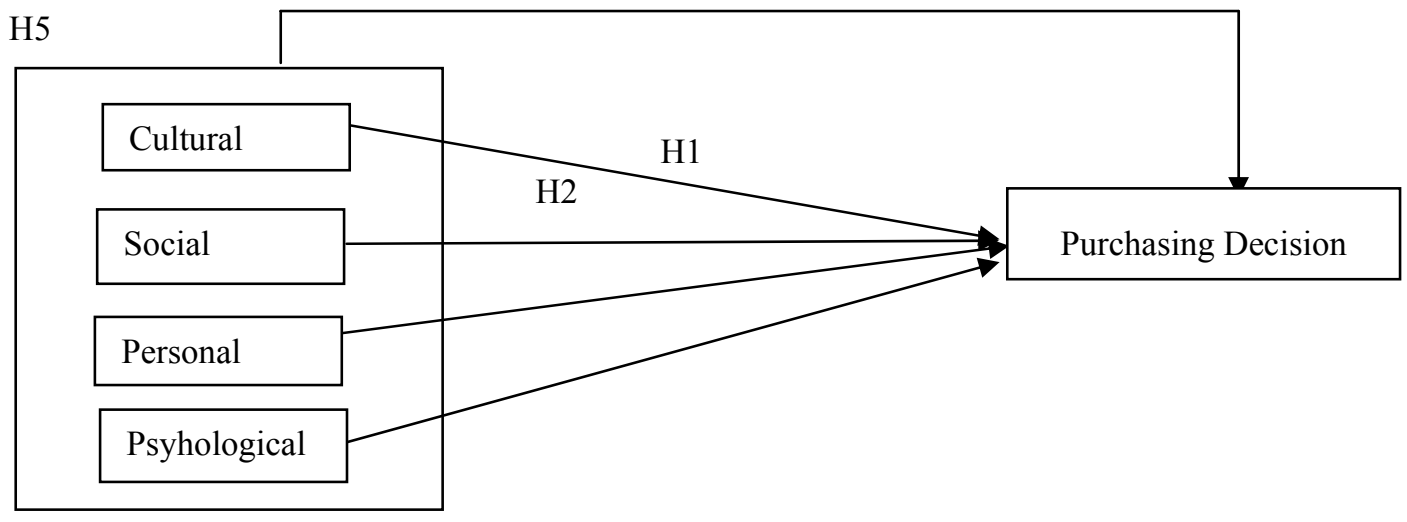

Figure 2 Relationship between ResearchVariables

(Source: Kotler, 2009) 
Based on the theoretical framework above, it can be formulated hypothesis as follows (a) There is a significant influence of cultural factors on students' decision in buying mobile brands BlackBerry; (b) There is a significant influence of social factors on students' decision in buying mobile brands BlackBerry; (c) There is a significant influence of personal factors on student's decision in buying mobile brands BlackBerry; (d)There is a significant influence of psychological factors on students' decision in buying mobile brands BlackBerry; (e)There is a significant influence of cultural factors, social, personal, and psychological factors to student' decisionin buying mobile brands BlackBerry.

\section{CONCLUSIONS}

Based on the analysis and discussion, it can be concluded that (1) There is a significant influence of cultural factors on purchasing decisions. (2) There is a significant influence of social factors on purchasing decisions. (3) There is a significant influence of personal factors on purchasing decisions. (4) There is a significant influence of psychological factors on purchasing decisions. (5) There is a significant influence of cultural, social, personal, and psychological simultaneously on purchasing decisions.

\section{REFERENCES}

Arikunto, S. (2010). Research Procedure A Practical Approach. Jakarta: Rineka Reserved.

Berkowitz, E. N., Kerin, R. A., \& Hartley, S. W. (2010). Marketing (6 ${ }^{\text {th }}$ Ed). NewYork: McGraw Hill.

Kotler, P. (2009 ). Marketing Management. Millennium Edition. Jakarta: Prenhalindo.

Kotler, P., \& Armstrong, G. (2012). Principles of Marketing $\left(14^{\text {th }}\right.$ Ed). New Jesey: Printice - Hall.

Kotler, P., Keller., Lane, K. (2012 ). Marketing Management (14 ${ }^{\text {th }}$ Global Ed). New Jesey: Printice Hall.

Lamb., Charles, W., Hair, J. F., McDaniel, C. (2010). Marketing. Jakarta: Salemba Empat.

Schiffman, L. G., \& Kanuk, L. L. (2011). Consumer Behavior $\left(9^{\text {th }}\right.$ Ed). New Jersey: Printice - Hall.

Sugiyono. (2012). Business Research Methods. Bandung: Alfabeta.

Swastha, B. D., \& Handoko, T. H. (2012). Marketing Management Consumer Behavior Analysis (4 ${ }^{\text {th }}$ Ed). Yogyakarta: BPFE.

Uddin, Md. R., Lopa, N. Z., \& Oheduzzaman, Md. (2014). Factors Affecting Customer's Buying Decisions Of Mobile Phone: A Study on Khulna City, Bangladesh. International Journal of Managing Value and Supply Chains (IJMVSC), 5 (2), 21 - 28.

Yakup, D., \& Jablonsk, S. (2012). Integrated Approach to Factors Affecting Consumers Purchase Behavior in Poland and an Empirical Study. Global Journal of Management and Business Research, 12(15), $60-87$. 